\title{
OS SERVIÇOS DE REFERÊNCIA EM BIBLIOTECAS UNIVERSITÁRIAS BRASILEIRAS
}

\author{
REFERENCE SERVICES IN BRAZILIAN UNIVERSITY \\ LIBRARIES
}

\author{
Ana Roberta Sousa Mota ${ }^{a}$ \\ Maria Manuel Borges
}

\begin{abstract}
RESUMO
Introdução: os serviços de referência modificam-se a partir da introdução das tecnologias da informação e da comunicação no meio acadêmico. Desde seu surgimento, no final do século XIX, ocorreram grandes mudanças, principalmente quando nos referimos ao acesso à enorme gama de dados e informações disponíveis. $\mathrm{O}$ artigo aborda conceitos de serviços de referência e retrata os serviços de referência nas bibliotecas universitárias brasileiras. Objetivo: caracterização dos bibliotecários de referência brasileiros e do meio no qual ocorrem os serviços de referência. Metodologia: integra elementos de pesquisa qualitativa e quantitativa. Para recolha de dados, fez-se uso do inquérito por questionário, elaborado e disponibilizado em meio digital à 40 bibliotecários atuantes em serviços de referência de bibliotecas universitárias brasileiras. Resultados: revelam uma maioria, feminina, com idades entre 35 e 40 anos, pós-graduadas há no máximo dez anos, com formação superior em Biblioteconomia atuando em biblioteca universitária há, no máximo, dez anos, e em serviços de referência há, no máximo, cinco anos, ligadas a alguma biblioteca central ou sistema de bibliotecas e que buscam a capacitação contínua, em cursos, treinamentos e eventos na área em que atua. Os serviços de referência ocorrem em meio digital e presencial, as principais fontes informacionais são o periódico, as teses e as dissertações, disponibilizadas e acessadas por meio dos recursos informacionais e o portal de periódicos eletrônicos e bases de dados, principalmente pelas áreas da saúde e biológicas. O processo de comunicação para a transação de referência ocorre predominantemente com a utilização de e-mail e telefone fixo. As redes sociais são utilizadas pela maioria das bibliotecas, sendo o Facebook e o Twitter as mais empregadas, principalmente na divulgação de produtos e serviços. A comunicação é realizada por bibliotecários, prevalecendo-se da língua portuguesa. Conclusões: os serviços de referência em bibliotecas universitárias brasileiras estão em plena expansão, tecnologias estão sendo inseridas à prática bibliotecária e os bibliotecários estão em busca de qualificação profissional com vistas a melhoria dos serviços que ofertam nas bibliotecas que atuam.
\end{abstract}

\footnotetext{
a Doutora em Informação e Comunicação em Plataformas Digitais pela Universidade do Porto Portugal. Bibliotecária na Universidade Federal da Paraíba, E-mail: anarobertamota@gmail.com.

b Doutora em Letras, área de Ciências Documentais, pela Universidade de Coimbra, Portugal. Professora Associada na Faculdade de Letras da Universidade de Coimbra, Portugal. E-mail: mmborges@gmail.com.
} 
Descritores: Serviço de Referência. Biblioteca Universitária. Gestão de Serviços em Bibliotecas.

\section{INTRODUÇÃO}

$\mathrm{O}$ artigo é fruto de pesquisa realizada no âmbito do doutoramento em Informação e Comunicação em Plataformas Digitais da Universidade do Porto, Portugal. Inicialmente, aborda-se conceitos relativos à serviços de referências, focando-se nas bibliotecas universitárias brasileiras, desde o surgimento desses serviços ao seu uso atualmente, abrangendo as tecnologias da informação e comunicação. $O$ artigo foi apresentado durante o Encontro Ibérico da Associação de Educação e Investigação em Ciência da Informação da Iberoamérica e Caribe (EDICIC), em 2019 (MOTA; BORGES, 2019), na cidade de Barcelona, Espanha.

Para compreender o foco central desse estudo, vamos aos primórdios dos serviços de referência, que são mencionados pela primeira vez em 1876, quando, Green, S. S. publica o artigo intitulado Personal Relations between Librarians and Readers no Library Journal e identifica quatro componentes do Serviço de Referência (SR): "1- Instruct the reader in the ways of the library; 2 Assists readers in solving their inquiries; $3-\mathrm{A}$ id the reader in the selection of good works; 4 - Promote the library within the community" (GREEN, 1876). Porém, os serviços de referência, surgem no final do século XIX nas bibliotecas públicas norte-americanas com o nome de reference services. Naquela época, devido à influência de Melvil Dewey e a adoção das Classificações de Dewey (CDD) e Decimal Universal (CDU) ocorre a abertura das bibliotecas para a democratização do acesso dos usuários aos acervos.

Pesquisador, renomado na área de serviços de referência em bibliotecas, Denis Grogan (1995, p. 8), reforça que o SR "é mais do que um expediente para a comodidade do usuário. Um dos factos da vida das bibliotecas é que grande parte do material constante do acervo precisa ser deliberadamente utilizado para proporcionar algum benefício". Para Grogan (1995), o trabalho de referência é muito mais do que uma técnica especializada ou uma habilidade profissional é uma atividade essencialmente humana, que atende a uma das necessidades mais profundas arraigadas da espécie, que é o anseio de conhecer e 
compreender.

Figueiredo (1996, p. 12), relata que o serviço de referência surgiu da percepção da necessidade de assistir os leitores no uso dos recursos da biblioteca. Isso ocorreu, portanto, sem qualquer estudo teórico, sem quaisquer métodos estabelecidos de desempenho ou procedimentos padronizados para medida e avaliação da eficiência dos serviços proporcionados. A autora aponta uma preocupação em definir pontos para corrigir a prestação de serviço de respostas às questões de referência, àquela época, a autora recomendava que o bibliotecário:

a) Obtenha a questão específica do usuário.

b) Demonstre interesse no usuário e na sua questão.

c) Demonstre atenção e preocupação para com o usuário e sua questão.

d) Pergunte ao usuário antes de completar a entrevista, se a informação recebida responde à questão de maneira completa.

e) Quando fornecendo a resposta à questão proposta, cite a fonte de onde a informação foi extraída.

f) Torne-se familiarizado com os tipos de informação disponível nas fontes de referência existentes na sua coleção (FIGUEIREDO, 1996, p.38).

Complementar às questões de referência, o processo de referência requer dos bibliotecários, no mínimo, duas habilidades: habilidade técnica e habilidade humana. Estas habilidades são imprescindíveis para encontrar a informação requerida pelos usuários. Figueiredo (1996) define estas habilidades como:

a) habilidade técnica é a capacitação dos bibliotecários de referência, para fazer uso de conhecimentos, métodos, técnicas e equipamento necessário para recuperar a informação;

b) habilidade humana é a capacidade e julgamento necessários, aos bibliotecários de referência, para lidar com pessoas, inclusive com conhecimentos dos diferentes níveis intelectuais dos indivíduos.

A definição proposta por Accart (2012, p. 181) para esse tipo de serviço é o que,

Oferece um ponto de acesso único em linha que o usuário pode identificar imediatamente, ao qual ele apresenta uma solicitação, entregue aos cuidados de profissionais qualificados, solicitação esta que enseja uma resposta rápida, pertinente e de qualidade.

Esse aspecto também é comentado por Mesquita (2011), ao destacar o serviço de referência como mister ao auxílio do usuário em suas necessidades 
informacionais e, neste momento, atribui ao profissional da informação a tarefa de orientar quanto ao uso do acervo e dos recursos disponíveis nas bibliotecas do ensino superior. Em paralelo às funções tradicionais, o profissional da informação, deverá exercer a função de mediação visando os novos serviços de informação. Para tanto, implica a aquisição de competências e saberes que complementem a capacidade técnica, proficiência, didática, comunicação etc.

Muito citado nas pesquisas que desvelam os SR, Accart (2012), aponta para os serviços de referência presenciais desenvolvidos várias direções: a partir da intensificação da profissionalização do atendimento, onde os responsáveis, tomadores de decisão têm muito cuidado ao selecionar e contratar uma equipe qualificada, insistindo nas competências sociais dos profissionais.

A entrevista de referência, indicada por Accart (2012) como privilegiada e não negligenciada, quando necessário, reforçar-se-á combinando a referência presencial com a virtual, haja vista que o futuro do serviço presencial parece estar nessa combinação com a tecnologia para ampliar o campo da referência tradicional, com intuito de alcançar o maior público fazer com que o público conheça mais sobre as bibliotecas e serviços de informação nas redes de informação. Accart (2012, p.5), reconhece que a

Sociedade da informação se apoia numa infinidade de
comunidades que possuem seus próprios interesses, o que
constitui toda sua riqueza. A associação da televisão com o
computador e do telefone celular com a internet representa uma
etapa marcante na complexa evolução das mídias.

A partir desta associação surge o Serviço de Referência Digital (SRD), como o meio de comunicação e disponibilização de informações para o usuário, onde, através dele, suas dúvidas deverão ser sanadas, procurando manter a personalização com o mesmo grau de proximidade que este exige, mesmo que emulado por via remota.

Em 1999, Janes, Carter e Memmott definem serviço de referência digital como "a mechanism by which people can submit their questions and have them answered by a library staff member through some electronic means (e-mail, chat, web forms, etc.)". A vertente tecnológica, da qual modifica os serviços de referência, é descrita por Johnson (2004), num estudo em duas bibliotecas universitárias do Atlântico Sul, onde os usuários foram indagados através do 
bate-papo (chat). No artigo, o autor afirma que,

Web-based library reference services have emerged as vital alternatives to the traditional face-to-face (FtF) or telephone reference encounter. Synchronous, (chat reference or Ask a Librarian services) and asynchronous (email) virtual reference services (VRS) have grown in number and become common features of both public and academic library home pages (JOHNSON, 2004, p. 245).

Um dos meios por onde ocorrem os SRD são os e-mails. Sobre isto, Márdero Arellano (2001, p. 2), relata que "os serviços de referência digital via correio eletrônico surgiram nos Estados Unidos no final da década de 1980, ao mesmo tempo em que as bibliotecas começaram a colocar seus catálogos na Internet." Esses serviços estão cada vez mais atuantes e há um avanço no interesse por essa área. Arellano (2001, p. 2) ressalta que

$\mathrm{Na}$ Internet podem ser encontradas bibliotecas que oferecem serviço de referência em tempo real, por meio do acesso à base de dados, telefone, e-mail, formulários na web, videoconferência, 'Internet chat', páginas de FAQ ou mural.

Ante o contexto de mudanças tecnológicas pelo qual passa o ambiente de atuação dos bibliotecários, Mota e Oliveira (2005), reforçam mudanças, não só no corpo de conhecimentos especializados, mas também em conhecimentos e habilidades no uso de tecnologias para organizar, processar, recuperar e disseminar informações, independentemente do suporte no qual elas estejam registradas". Araújo e Dias (2005, p. 120) argumentam que o bibliotecário deve assumir uma postura proativa em relação ao usuário, o que exige deste profissional "uma postura de antecipação às necessidades de informação ao usuário. Um exemplo de reação proativa é o oferecimento, por parte da biblioteca, de treinamento de usuários para a utilização de redes de comunicação eletrônica".

Há anos, Cunha (2000) escrevia que no futuro do serviço de referência eletrônica existirá um programa de computador, denominado "agente inteligente", que terá como objetivo executar funções como: extrair palavraschave da expressão de busca elaborada pelo usuário remoto, adicionará sinônimos, organizará o resultado em uma estrutura hierárquica e enviará o resultado preliminar para o usuário. Este poderá fazer alterações e adicionar novos parâmetros, por exemplo, o período coberto e o tipo de documento. Dentro 
desta perspectiva,

As atividades de educação do usuário, tradicionalmente executadas pelo serviço de referência, deverão ter mudanças, mas os bibliotecários ainda continuarão a ensinar as pessoas a fazer melhor proveito dos recursos informacionais existentes na biblioteca, ou mesmo na Internet (CUNHA, 2000, p.83).

O contexto apresentado pelas Tecnologias de Informação e Comunicação (TIC) em plataformas digitais, leva-nos a ressaltar que a história dos serviços de referência digitais é recente, com os "primeiros serviços implantados no final da década de 1990, nos Estados Unidos e na Escandinávia" (ACCART, 2012, p. 164).

Merlo-Vega (2009) ao afirmar que

Los servicios de referencia digital se basan en tecnologías, tanto para la comunicacíon con los usuarios, como para la resolucíon de las consulta" e que "entre las tecnologías utilizada destacan: correo electrónico, chat, formularios web, mensajería instantánea, redes sociales, entornos virtuales, mensajería móvil, etc (MERLO-VEGA, 2009, p. 593).

Os serviços de referência digital definido por Merlo-Vega (2009) baseiamse na interação entre usuário e bibliotecário, por meio da comunicação em plataformas digitais.

Carrie Moran (2010, p. 2) aborda a referência digital como

Any service provided to users that can be accessed remotely. This definition encompasses email and chat reference, library websites, and Web 2.0 technologies. Digital reference services are used in academic libraries for traditional reference work, library instruction, and the provision of internet resources for enduser searching.

O serviço de referência digital colabora no atendimento à necessidade informacional do usuário, e mesmo os serviços ofertados presencialmente podem ser acessados remotamente, como a orientação ao usuário, busca por fontes e recursos informacionais e o fornecimento da resposta ao usuário final.

A Reference and Information Services, seção subordinada à divisão Library Services da International Federation of Library Associations and Institutions $^{1}$ (IFLA) tem como objetivo abordar os aspectos do trabalho de

\footnotetext{
1 Is the leading international body representing the interests of library and information services and their users. It is the global voice of the library and information profession Disponível em: http://www.ifla.org/about.
} 
referência, em todos os tipos de biblioteca, em todas as regiões do mundo.

Vale salientar que os bibliotecários, principalmente os de referência, deverão conhecer as novas tecnologias, transformando o instrumento da referência tradicional para uma referência digital visando maior abrangência e competitividade das bibliotecas no mercado informacional. Por esta razão, Lopes e Silva (2006, p. 1) ressaltam o avanço e a incorporação das TIC, especificamente da Internet nas atividades das unidades de informação ocorreu um deslocamento de objetivos dessas instituições, pois passaram a visualizar a sua atuação e o fluxo de suas atividades através de um novo paradigma, o paradigma de acesso à informação, em substituição ao paradigma de posse da informação.

Inevitavelmente, a biblioteca universitária utiliza as TIC para satisfazer a necessidade do usuário e, como bem compreende a $A C R L$, os bibliotecários acadêmicos devem estar cientes das pesquisas em humanidades digitais, eles são parceiros naturais, principalmente, devido às suas experiências com os repositórios digitais ou as bibliotecas digitais. $O$ ensino à distância e principalmente a experiência em busca, acesso e uso de informações trouxeram uma nova realidade aos serviços de referência, principalmente com 0 atendimento em meio digital.

Diante dessa realidade hodierna, os recortes trazidos, a partir das leituras realizadas, levam a compreensão de que o serviço de referência, responsável pela mediação entre a informação e o usuário, tem sofrido, como outros, transformações decorrentes do surgimento da Web e das TIC em geral. Seus serviços foram modificados para atender ao público não apenas de forma presencial, como também ao público geograficamente distante, através de atendimento remoto. É, assim, em virtude do uso da tecnologia digital e de redes e a consequente disponibilização de informação e de serviços em meio digital que os bibliotecários têm procurado atender às necessidades dos usuários, o que requer um perfil diferenciado do tradicional mais exigente do ponto de vista da literacia digital.

Tarapanoff, Suaiden e Oliveira (2002) salientam que os profissionais da informação devem, assim como os professores, tornarem-se animadores da 
inteligência coletiva dos cidadãos e dos estudantes, oferecendo ferramentas intelectuais para que os indivíduos cooperem e produzam conhecimentos em grupo. Para desempenhar seu papel de animador da inteligência coletiva, deve ser um mediador da informação no mundo digital e, deverá ter a capacidade real de entendimento do receptor da informação, garantindo a efetiva comunicação e a satisfação da necessidade informacional do usuário dessa tecnologia.

Outro fator importante que merece destaque, refere-se ao que tem ocorrido especificamente no ambiente digital, a partir da introdução das TIC nas bibliotecas, abordado por Silva e Lopes (2011) como "deslocamento de objetivos dessas instituições, que passaram a visualizar a sua atuação e o fluxo de suas atividades [por meio] de um novo paradigma, o paradigma de acesso à informação, em substituição ao paradigma de posse da informação, o que as tornou vulneráveis ao fenômeno da desintermediação.

O novo paradigma proporciona maior autonomia aos usuários, devido ao aumento de informações disponibilizadas por meio da rede, diminuindo assim, a intervenção do bibliotecário no processo de busca da informação. A falta de contato entre bibliotecários e usuários é chamado de desintermediação da informação. Neste sentido, Carvalho e Silva (2009, p.130) afirmam que "as rotinas de trabalho, a forma de percepção de fontes de informação ligadas à noção de desterritorialização da informação, bem como a relação com os usuários (reais/virtuais) em detrimento da exclusividade da fonte bibliográfica e a noção custodial e tecnicista, são potencialmente atingidos por essas inovações".

Contudo, percebe-se que os SR modificam-se a partir da introdução das TIC no meio acadêmico. Desde seu surgimento, no final do século XIX, até os dias atuais, ocorreram grandes mudanças, principalmente quando nos referimos ao acesso à enorme gama de dados e informações disponíveis. A sociedade da informação tem acessado informações com variados formatos e extensões através das plataformas digitais móveis e não móveis. O conceito inicial dos serviços de referência se mantém - atender à necessidade informacional do usuário - porém, o lugar onde estão ocorrendo as interações, e, as habilidades exigidas ao profissional da informação se modificaram, demandando maior 
diálogo com áreas tecnológicas e de estudos de comportamento para utilização de sistemas informacionais.

Dentro desta perspectiva e mudança paradigmática, do tradicional para o digital, da guarda para a sociabilização do acesso apresenta-se como objetivo deste artigo a caracterização dos bibliotecários de referência brasileiros e do meio no qual ocorrem os serviços de referência.

\section{METODOLOGIA EMPREENDIDA}

Utilizou-se de uma abordagem mista, contemplando os enfoques quantitativos e qualitativos. Neste sentido, sobre o enfoque qualitativo, Sampieri, Collado e Lúcio (2013) afirmam que ser pesquisador qualitativo é descobrir e refinar as questões de pesquisa, utilizar coleta de dados sem medição numérica para descobrir ou aperfeiçoar questões de pesquisa e pode ou não provar hipóteses em seu processo de interpretação.

Para a identificação das biblioteca a serem investigadas, utilizou-se de plataforma do Ministério da Educação do Brasil (e-MEC) para saber quais universidades seriam inqueridas, contudo, a plataforma retornou um número de 197 universidades, e por isto, fez-se um recorte de aproximadamente $20 \%$, totalizando 40 bibliotecas, divididas em 5 regiões brasileiras (Norte, Nordeste, Centro-Oeste, Sudeste e Sul). Para viabilizar a investigação, delimitou-se o campo empírico a partir da verificação das universidades com maior Índice Geral de Cursos (IGC), indicador de qualidade que avalia as instituições de educação superior no Brasil. Em seguida, observou-se o Conceito Institucional $(\mathrm{Cl})$ para seleção de 8 (oito) universidades em cada uma das cinco regiões, totalizando um universo de 40 universidades.

Para a recolha de dados, fez-se uso do instrumento questionário, elaborado pela pesquisadora por meio do google forms e enviado aos e-mails de 40 bibliotecas universitárias brasileiras, com a disponibilização de um link de acesso ao questionário. Inicialmente, por meio do uso de questionário, buscouse elucidar questões relacionadas ao serviço de referência, perguntando sobre: meio em que ocorre o SR, plataformas digitais utilizadas, áreas do conhecimento que utilizam os SR, fontes de informação disponibilizadas, meios para 
comunicação, uso de redes sociais e suas funções, quem são os agentes disseminadores e que idiomas utilizam durante o processo de referência. Para isto, levantou-se as características relevantes dos bibliotecários de referência, tais como: sexo, idade, escolaridade e o tempo de término da mesma, área de formação, tempo de atuação em biblioteca universitária e em serviços de referência, biblioteca ou sistema de bibliotecas em que atua, participação em treinamentos, cursos de aperfeiçoamento e eventos na área de atuação, bem como a regularidade nessas participações.

Posteriormente, ainda com uso do questionário, recolheu-se informações relacionadas aos serviços de referência das bibliotecas universitárias inquiridas. Perguntou-se sobre: meios dominantes onde ocorre o processo de referência; plataformas digitais empregadas; áreas do conhecimento que mais se valem deste serviço; tipos de fontes de informação; meios e comunicação; uso de redes socais, quais são e para qual finalidade; quem são os agentes disseminadores e, por último, quais idiomas eles utilizam para se comunicar com os usuários.

\section{RESULTADOS E DISCUSSÃO}

Os Serviços de Referência Digital (SRD) em Bibliotecas Universitárias Brasileiras (BUB) apresentam-se, neste artigo, divididos em duas partes, que tratam da caracterização do bibliotecário de referência e dos serviços de referência.

\subsection{Os BibLIOTECÁRIOS DE REFERÊNCIA}

A caracterização dos bibliotecários de referência de universidades brasileiras apresenta-se com a indicação do gênero, idade, escolaridade, atuação profissional e capacitação dos mesmos.

Para a caracterização dos bibliotecários, o resultado obtido, visto no Gráfico 1, indica a maioria do sexo feminino (80\%). Logo, pode-se afirmar que se trata de uma atividade predominantemente feminina. 


\section{Gráfico 1 - Distribuição por sexo dos bibliotecários de referência N=40}

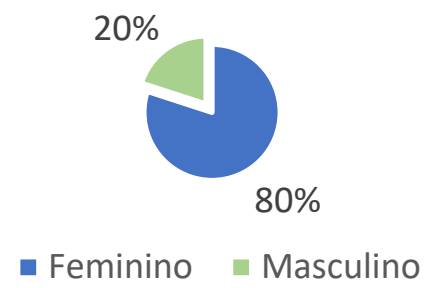

Fonte: dados da pesquisa, 2016.

Com relação à idade dos bibliotecários de referência, em pergunta aberta e obrigatória, solicitou-se ao respondente a indicação de sua idade. Os resultados, sumariados na Tabela 1 , revelam-se que a maioria dos bibliotecários estão inseridos na faixa etária dos 35 aos 40 anos (31\%). Seguidamente, identifica-se bibliotecários entre 29 e 34 anos (26\%), com idades entre 47 e 52 anos (15\%) e, nos extremos, com menor incidência, aponta-se para as idades de: 41 a 46 (13\%), 23 a 28 (10\%) e 53 a 58 (5\%). Por conseguinte, percebe-se que os bibliotecários de referência têm menos de 40 anos em sua maioria (67\%), evidenciando uma maioria de nativos digitais e uma minoria de imigrantes digitais, o que indica maior familiaridade e habilidade no uso de TIC, vivenciada pelos mesmos desde o nascimento para uso efetivo de toda gama tecnológica empregada hodiernamente nas bibliotecas universitárias.

Tabela 1 - Idade, escolaridade e área de formação

\begin{tabular}{lcc}
\hline \multicolumn{1}{c}{ Idade } & Frequência absoluta & Frequência relativa (\%) \\
\hline 23 a 28 anos & 4 & 10 \\
29 a 34 anos & 10 & 26 \\
35 a 40 anos & 12 & 31 \\
41 a 46 anos & 5 & 13 \\
47 a 52 anos & 6 & 15 \\
53 a 58 anos & 2 & 5 \\
\hline Escolaridade & Frequência absoluta & Frequência relativa (\%) \\
\hline Ensino superior & 5 & 12,5 \\
Especialização & 26 & 65 \\
Mestrado & 8 & 20 \\
Doutorado & 1 & 2,5 \\
\hline Há quanto tempo terminou o & Frequência absoluta & Frequência relativa (\%) \\
ciclo de estudos que define & & 8
\end{tabular}




\begin{tabular}{lcc} 
1a 5 anos & 17 & 46 \\
6 a 10 anos & 10 & 27 \\
11 a 15 anos & 2 & 5,5 \\
16 a 20 anos & 3 & 8 \\
Mais de 20 anos & 2 & 5,5 \\
\hline Área de formação profissional & Frequência absoluta & Frequência relativa (\%) \\
\hline Biblioteconomia & 39 & 97,5 \\
Ciência da Informação & 7 & 17,5 \\
Administração & 1 & 2,5 \\
Pedagogia & 1 & 2,5 \\
Gestão de Pessoas & 1 & 2,5 \\
Docência do ensino superior & 1 & 2,5 \\
Marketing & 1 & 2,5
\end{tabular}

Fonte: dados da pesquisa, 2016.

Para caracterizar a escolaridade dos profissionais de informação que atuam nos serviços de referência, fez-se necessário abordar questões relativas à escolaridade, grau de escolaridade, tempo de término no ciclo de estudos que determina o grau de escolaridade e área de formação predominante destes profissionais. Para isto, indagou-se sobre que nível de escolaridade tinham, há quanto tempo haviam terminado o ciclo de estudos que determinavam seu grau de escolaridade e qual sua área de formação profissional.

Na primeira pergunta, fechada, de caráter obrigatório, identifica-se o grau de escolaridade. As respostas revelam (Tabela 1) que a maioria dos respondentes, é composta por especialistas (65\%), mestres $(20 \%)$ e doutores (2,5\%). Além disto, identificou-se que, $12,5 \%$ dos bibliotecários têm, apenas, 0 ensino superior. Ressalta-se, ainda, que ao somar-se os profissionais com especialização, mestrado e doutorado, o resultado indica que $87,5 \%$ são pósgraduados em detrimento aos $12,5 \%$ graduados, comprovando que os bibliotecários estão buscando o aperfeiçoamento de seus conhecimentos adquiridos para além da graduação. A busca pela capacitação revela a necessidade de aprender para compreender melhor seu universo de atuação.

Pode-se afirmar que, nos últimos anos, os bibliotecários de referência estão capacitando-se, incluindo o nível de doutorado.

Complementarmente, para averiguação das características relativas à escolaridade com vistas a identificar se há capacitação contínua dos 
bibliotecários, perguntou-se: há quanto tempo terminou o ciclo de estudos que determina a sua escolaridade.? Vale esclarecer que se tratou de uma questão aberta, e, para quantificar as respostas, elaborou-se uma escala com intervalos de cinco anos. A esta pergunta obteve-se 37 respostas válidas, como pode se ver na Tabela 1. Sendo assim, o resultado anuncia que a maioria dos bibliotecários (46\%) terminaram o curso entre um e cinco anos passados, enquanto a minoria absoluta, (5,5\%) terminaram há mais de 20 anos.

Indagados acerca da área de formação, tabela 1, os profissionais atuantes em serviços de referência de bibliotecas universitárias brasileiras, maioritariamente, responderam ter formação na área de Biblioteconomia (97,5\%), alguns apontaram a Ciência da Informação (17,5\%), assim como, as áreas de Administração (2,5\%), Pedagogia (2,5\%), gestão de pessoas $(2,5 \%)$, docência no ensino superior (2,5\%) e Marketing (2,5\%). O resultado confirma que os bibliotecários respondentes atuam de forma dominante nos serviços de referência em bibliotecas universitárias brasileiras (Tabela 4). Tal corolário revela-se, principalmente, devido à aplicabilidade da Lei 4.084 de 30 de junho de 1962, que em seu Art. 20 estabelece:

O exercício da profissão de Bibliotecário, em qualquer de seus ramos, só será permitido: a) aos Bacharéis em Biblioteconomia, portadores de diplomas expedidos por Escolas de Biblioteconomia de nível superior, oficiais, equiparadas, ou oficialmente reconhecidas (BRASIL. PRESIDÊNCIA DA REPÚBLICA, 1962)

Importa esclarecer que a aplicabilidade da Lei 4.084/62 e a fiscalização do exercício da Profissão do Bibliotecário é exercida pelo Conselho Federal de Biblioteconomia e pelos Conselhos Regionais de Biblioteconomia.

Ainda sobre a caracterização dos bibliotecários, faz sentido perceber 0 tempo de atuação profissional para identificar-se o fator experiência no momento da mediação da informação, pois, neste mesmo sentido, Grogan (1995) justifica que para ser um bom bibliotecário de referência, deve-se ter, no mínimo, dez anos de experiência. Isto porque é a prática que vai permitir ao profissional ser competente para exercer esta função.

Diante das respostas, elencadas, em escalas, na Tabela 2, pode-se afirmar que o resultado não está inserido dentro da perspectiva Groganiana, haja 
vista que a maior parte dos bibliotecários de referência $(67,5 \%)$ afirmaram atuar em biblioteca universitária há menos de 10 anos, enquanto que a minoria declarou estar no campo de atuação há mais de 10 anos (32,5\%).

Tabela 2 - Atuação profissional em biblioteca universitária e em serviços de referência

\begin{tabular}{lcc}
\hline $\begin{array}{c}\text { Tempo de atuação profissional em } \\
\text { biblioteca universitária }\end{array}$ & Frequência absoluta & Frequência relativa (\%) \\
\hline Menos de 1 ano & 1 & 2,5 \\
1 a 5 anos & 11 & 27,5 \\
a 10 anos & 15 & 37,5 \\
11 a 15 anos & 4 & 10 \\
16 a 20 anos & 4 & 10 \\
Mais de 20 anos & 5 & 12,5 \\
\hline Tempo de atuação profissional em & Frequência absoluta & Frequência relativa (\%) \\
\multicolumn{1}{c}{ serviços de referência } & 4 & 11 \\
\hline Menos de 1 ano & 18 & 49 \\
1 a 5 anos & 6 & 16 \\
a 10 anos & 4 & 11 \\
11 a 15 anos & 4 & 8 \\
16 a 20 anos & 2 & 5 \\
Mais de 20 anos & 2 & \\
\hline
\end{tabular}

Fonte: Dados da pesquisa, 2016.

O tempo de atuação profissional em serviços de referência é abordado seguidamente, resultando no demonstrado na Tabela 2 (dois): maioria dos bibliotecários de referência atuam em SR há cerca de um a cinco anos (49\%) enquanto que a minoria (5\%) atua há mais de 20 anos. Outros intervalos são indicados pelos respondentes, a saber: menos de um ano (11\%), seis a dez anos (16\%), 11 a 15 anos (11\%) e 16 a 20 anos (8\%). Claramente, percebe-se que a maioria dos bibliotecários de referência atuam neste serviço há menos de 10 anos, totalizando um valor de $76 \%$ dentre os 37 respondentes.

Com relação à designação assumida pelas bibliotecas, os respondentes indicaram que 13 bibliotecas são denominadas como biblioteca central, 15 como sistema de bibliotecas, 8 levam o nome da universidade em sua designação, duas utilizam-se do termo biblioteca universitária e, duas biblioteca da universidade. $\mathrm{O}$ Quadro 1 explicita as respostas dos 40 inquiridos nesta investigação científica. Vale ressaltar que a terminologia adotada como sistema de bibliotecas, assumida pela maioria dos bibliotecários inquiridos, diz respeito a um conjunto de bibliotecas de uma universidade, na qual está ligada, geralmente tendo a biblioteca central 
como coordenadora, regido por normas e regulamentos próprios. Os sistemas de bibliotecas estão inseridos dentro das universidades, bem como seus regulamentos e normas são de responsabilidade de cada universidade, em consonância com os objetivos das universidades na qual estão ligadas.

\section{Quadro 1- Biblioteca e/ou sistema de biblioteca pertencente}

\begin{tabular}{|c|}
\hline $\begin{array}{c}\text { Nomenclatura assumida pelos respondentes } \\
\text { Biblioteca Universitária da Universidade Federal de Lavras (UFLA) }\end{array}$ \\
\hline Biblioteca Central UFGD. \\
\hline Sistema de Bibliotecas da Universidade Federal Rural do Semiárido. \\
\hline Sistema de Bibliotecas da Universidade Federal do Rio Grande do Norte. \\
\hline Biblioteca da Universidade Positivo. \\
\hline Universidade Católica de Brasília (UCB). \\
\hline Biblioteca Central Cesar Lattes - UNICAMP. \\
\hline Sistema de Bibliotecas da Universidade Federal do ABC. \\
\hline UFMS. \\
\hline SIBI UNIVASF. \\
\hline Biblioteca Central da Universidade Federal de Roraima. \\
\hline Biblioteca Central do Sistema de Bibliotecas da Universidade de Caxias do Sul. \\
\hline SiBi/UFPR. \\
\hline Sistema de Bibliotecas da UFBA. \\
\hline Sistemas de Bibliotecas da Universidade Federal do Amazonas. \\
\hline $\begin{array}{l}\text { Sistema de Biblioteca da Universidade Federal de Mato Grosso. Biblioteca Regional de } \\
\text { Rondonópolis. }\end{array}$ \\
\hline Biblioteca Central da UFCG. \\
\hline Biblioteca Central da UFPE. \\
\hline Sistema de Bibliotecas da Universidade Federal de Goiás (SiBi/UFG). \\
\hline Sistema de Bibliotecas da Universidade Federal do Rio Grande do Sul. \\
\hline Universidade Católica Dom Bosco. \\
\hline Unisc. \\
\hline UNIC - Universidade de Cuiabá. \\
\hline Sistema de Bibliotecas da UNAMA. \\
\hline Sistema de Biblioteca UFPB. \\
\hline Biblioteca Central da Universidade de Brasília. \\
\hline $\begin{array}{l}\text { Universidade Federal Rural de Pernambuco - Sistema Integrado de Bibliotecas - Biblioteca } \\
\text { Central. }\end{array}$ \\
\hline Biblioteca Central UFMG / Sistema de Bibliotecas da UFMG. \\
\hline Biblioteca Universitária da UFSC. \\
\hline Biblioteca da Universidade Tecnológica Federal do Paraná - Campus Cornélio Procópio. \\
\hline $\begin{array}{l}\text { Biblioteca Central da UFRA - Lourenço José Tavares Vieira da Silva - Sistema de Biblioteca } \\
\text { ainda em construção. }\end{array}$ \\
\hline SISBIB / UFT (Universidade Federal do Tocantins). \\
\hline Biblioteca Central do Sistema de Bibliotecas da Universidade Federal do Pará. \\
\hline Biblioteca Central da UFV. \\
\hline Biblioteca Aderson Dutra. Sistema Integrado de Bibliotecas - SIBIB. \\
\hline Biblioteca Unisinos. \\
\hline Biblioteca da UNIFESP, campus São Paulo. \\
\hline Biblioteca Central da Universidade Federal do Acre. \\
\hline SIBi UFSCar Biblioteca Comunitária. \\
\hline
\end{tabular}

Fonte: Dados da pesquisa, 2016. 
Após a identificação das características relacionadas à formação profissional e nomenclaturas adotadas pelas bibliotecas universitárias brasileiras, a investigação ocupou-se em inquirir a respeito de treinamentos/aperfeiçoamentos em eventos especializados. Para isso, elaborou-se uma pergunta fechada, subdivida em três indagações: participou de treinamento/aperfeiçoamento antes de iniciar o atendimento ao usuário? Participou de curso de aperfeiçoamento relacionado à sua área de atuação? Participa de eventos relacionados a biblioteca universitária ou área correlacionada?

Fruto da primeira indagação, 21 bibliotecários inquiridos revelaram ter participado, enquanto 19, disseram não haver participado, conforme ilustra-se na Tabela 3. A segunda indagação revela-se numa afirmativa de 29 respondentes, em oposição a 11 negativas. Enquanto, na terceira indagação, expõe-se uma quantidade expressiva de participantes (33) em eventos relacionados à biblioteca universitária ou área correlacionada, diferentemente do número de não participantes deste tipo de evento (7).

Contudo, percebe-se que a maioria dos bibliotecários têm participado de treinamentos, aperfeiçoamentos e eventos relacionados à sua área de atuação, corroborando o que aconselha Dudziak (2003, p. 33), ao declarar que os bibliotecários,

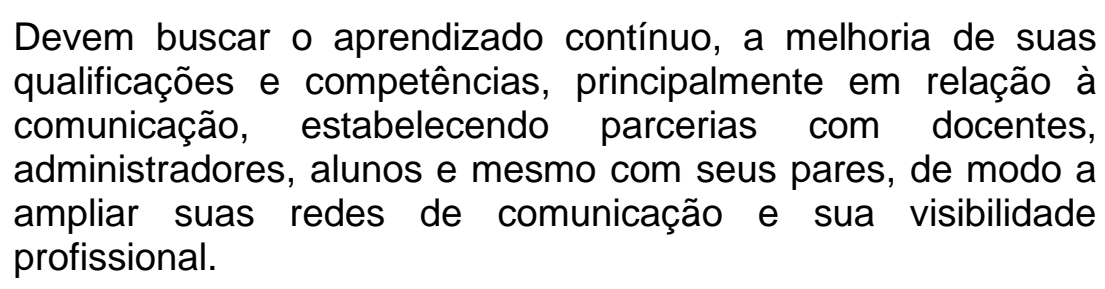

A participação em treinamento antes de iniciar o atendimento ao usuário, em curso de aperfeiçoamento e em eventos na área de atuação ratificam a busca pelo aprendizado contínuo ao longo da vida para melhoria e maior abrangência de suas competências informacionais.

Tabela 3- Participação em eventos em área de biblioteca universitária

\begin{tabular}{lcccc} 
Treinamento/Aperfeiçoamento e eventos especializados & $\underset{\mathbf{S}}{\operatorname{Sim}}$ & $\begin{array}{c}\text { Sim } \\
\%\end{array}$ & $\begin{array}{c}\text { Não } \\
\text { N }\end{array}$ & $\begin{array}{c}\text { Não } \\
\%\end{array}$ \\
\hline $\begin{array}{l}\text { Participou de treinamento antes de iniciar o atendimento ao } \\
\text { usuário? }\end{array}$ & 21 & 52,5 & 19 & 47,5 \\
$\begin{array}{l}\text { Participou de curso de aperfeiçoamento relacionado à sua área } \\
\text { de atuação? }\end{array}$ & 29 & 72,5 & 11 & 27,5
\end{tabular}


Participa de eventos relacionados a biblioteca universitária ou área correlacionada?

$33 \quad 82,5 \quad 7 \quad 17,5$

\begin{tabular}{lcc}
\hline $\begin{array}{c}\text { Há quanto tempo frequentou o último curso de } \\
\text { aperfeiçoamento na sua área de atuação? }\end{array}$ & $\begin{array}{c}\text { Frequência } \\
\text { absoluta }\end{array}$ & $\begin{array}{c}\text { Frequência } \\
\text { relativa (\%) }\end{array}$ \\
\hline Menos de 1 ano & 17 & 57 \\
1a 2 anos & 7 & 23 \\
3 a 4 anos & 5 & 17 \\
5 a 6 anos & 1 & 3 \\
\hline Há quanto tempo foi sua última participação em evento? & $\begin{array}{c}\text { Frequência } \\
\text { absoluta }\end{array}$ & $\begin{array}{c}\text { Frequência } \\
\text { relativa (\%) }\end{array}$ \\
\hline Menos de 1 ano & 13 & 41 \\
1a 2 anos & 14 & 44 \\
3 a 4 anos & 5 & 16 \\
\hline
\end{tabular}

Fonte: Dados da pesquisa, 2016.

Dando continuidade à investigação, com o objetivo de identificar a temporalidade das participações dos bibliotecários em eventos e capacitações, perguntou-se sobre o tempo decorrido desde a conclusão do último curso de aperfeiçoamento/treinamento em sua área de atuação. Nesse sentido, indica-se que a maioria (57\%) frequentou curso de aperfeiçoamento há menos de um ano, seguidamente de outros $23 \%$ que frequentaram entre um e dois anos, $17 \%$ de três a quatro anos e $3 \%$ de cinco a seis anos (Tabela 3 ).

Os percentuais demonstram uma comunidade bibliotecária participante e atuante em eventos da biblioteconomia brasileira convergindo com que Vitorino e Piantola (2009, p.131), asseveram ao afirmarem que "os novos paradigmas de velocidade e de transformação que configuram a sociedade demandam que o indivíduo estabeleça uma nova relação com a informação e com o saber, uma relação de aprendizado ao longo da vida". Isto posto, o resultado revela-se na intenção do aprendizado ao longo da vida como algo real, principalmente pelo facto da maioria ter frequentado curso de aperfeiçoamento há menos de um ano e a minoria há 5 ou 6 anos.

Sobre o tempo decorrido entre a última participação em evento e a época de resposta ao questionário, apenas 32 inquiridos responderam à questão, indicando que, em sua maioria (44\%), participaram de eventos há um ou dois anos (Tabela 3). Ainda se constatou que $41 \%$ dos respondentes informou ter participado há menos de um ano e 16\%, há três ou quatro anos. Importa elucidar que as escalas foram elaboradas baseadas nas respostas da pergunta aberta, respeitando um intervalo de um a dois anos. 


\subsection{Os SERVIÇOS DE REFERÊNCIA}

O contexto vivenciado pelos serviços de referência hodiernamente propicia a necessidade de abordar-se junto aos bibliotecários, acerca dos meios onde ocorrem os serviços de referência, as plataformas digitais, quais áreas do conhecimento, fontes informacionais, meios de comunicação, agentes disseminadores e idiomas operantes no processo de referência. Nesta lógica, perguntou-se: o processo dominante de referência ocorre em que tipo de regime? Quais as principais plataformas digitais utilizadas? Quais áreas do conhecimento mais utilizam os SR da biblioteca? Quais tipos de fontes que a biblioteca dá acesso em plataformas digitais? Principais dispositivos utilizados para a comunicação durante a transação de referência? A biblioteca utiliza redes sociais para o SR? Quais? Com que finalidade? Quem são os agentes disseminadores de informações? E quais idiomas utilizados durante o processo de referência?

A respeito do meio dominante onde ocorre o processo de referência, averiguou-se que há uma igualdade de valores referentes ao meio dominante pelo qual ocorre o processo de referência nas bibliotecas universitárias, consoante 0 demonstrado no Gráfico 2. Indica-se $48 \%$ para o meio presencial e $48 \%$ para o híbrido, que engloba atendimento presencial e digital. O meio digital é apontado por $4 \%$ dos respondentes como meio dominante onde ocorre o processo de referência. Percebe-se que o meio digital está inserido em grande parte das respostas, enquanto o meio presencial foi indicado pela maioria somando-se o híbrido (contempla presencial e digital) com o presencial. O resultado revela que os serviços presenciais e híbridos predominam em relação ao meio digital.

\section{Gráfico 2- Meio dominante onde ocorre o processo de referência}



Fonte: Dados da pesquisa, 2016 
Com relação à plataforma digital, numa questão de múltipla escolha, pediu-se aos bibliotecários para apontarem as principais plataformas digitais utilizadas, entre (Tabela 4): Portal de periódicos científicos (95\%), Bases de dados científicas (88\%), Catálogo online e Biblioteca Digital (70\%), Portal de Teses e dissertações (68\%), Repositório Institucional (60\%) e, base de dados local (3\%).

Tabela 4- Plataformas digitais, áreas do conhecimento e fontes utilizadas em serviços de referência de bibliotecas universitárias

\begin{tabular}{lcc}
\hline \multicolumn{1}{c}{$\begin{array}{c}\text { Principais plataformas digitais } \\
\text { utilizadas }\end{array}$} & Frequência absoluta & Frequência relativa (\%) \\
\hline Catálogo online (OPAC) & 28 & 70 \\
Bases de dados científicas & 35 & 88 \\
Biblioteca Digital & 28 & 70 \\
Repositório Institucional & 24 & 60 \\
Portal de periódicos científicos & 38 & 95 \\
Portal de teses e dissertações & 27 & 68 \\
Base local & 1 & 3 \\
\hline \multicolumn{1}{c}{ Área do conhecimento } & Frequência absoluta & Frequência relativa (\%) \\
\hline Ciências Exatas e da Terra & 22 & 55 \\
Ciências Biológicas & 26 & 65 \\
Engenharias & 24 & 60 \\
Ciências da Saúde & 26 & 65 \\
Ciências Agrárias & 14 & 35 \\
Ciências Sociais Aplicadas & 23 & 58 \\
Ciências Humanas & 24 & 60 \\
Linguística, Letras e Artes & 17 & 43 \\
\hline Fontes a que a biblioteca dá acesso & Frequência absoluta & Frequência relativa (\%) \\
\multicolumn{1}{c}{ em plataformas digitais } & 30 & 75 \\
Livros & 37 & 93 \\
Periódicos & 10 & 25 \\
Enciclopédias & 9 & 23 \\
Dicionários & 5 & 13 \\
Patentes & 19 & 48 \\
Normas técnicas & 3 & 8 \\
Projetos & 35 & 88 \\
Teses, dissertações e TCC & &
\end{tabular}

Fonte: Dados da pesquisa, 2016.

As áreas do conhecimento apontadas pelos bibliotecários, Tabela 4, como as que mais utilizam-se dos serviços de referência foram determinadas com base na Tabela de áreas da CAPES. No resultado apontou-se: Ciências da Saúde e Ciências Biológicas (65\%), Engenharias e Ciências Humanas (60\%), Ciências Sociais Aplicadas (58\%), Ciências Exatas e da Terra (55\%), Linguística, Letras e Artes (43\%) e, Ciências Agrárias (35\%). Observa-se que as Ciências da Saúde e Ciências Biológicas são as áreas que mais utilizam os SR, enquanto as 
Ciências Agrárias são as que menos utilizam os serviços de referência, de acordo com os bibliotecários respondentes.

As fontes de informação, acessíveis em plataformas digitais, revelam-se, a partir dos resultados explicitados na Tabela 4, da seguinte forma: periódicos $(93 \%)$, teses e dissertações (88\%), livros $(75 \%)$, normas técnicas $(48 \%)$, enciclopédias (25\%), dicionários $(23 \%)$, patentes $(13 \%)$ e projetos $(8 \%)$. Contudo, demonstra-se que a maioria das fontes informacionais estão disponíveis em forma de periódicos, teses e dissertações e livros. Devido à caracterização das fontes informacionais disponibilizadas pela biblioteca através do acesso em meio digital, pode-se afirmar que o resultado obtido manifesta uma necessidade de encontro com as fontes primárias por parte dos usuários das informações, disponibilizadas em plataformas digitais.

Mediante a necessidade de identificar os meios e formas dos bibliotecários se comunicarem com os usuários, perguntou-se sobre os principais dispositivos utilizados durante a transação de referência, a utilização de redes sociais na referência, assim como quais as redes, com que finalidade as utilizam, quem são os agentes disseminadores da informação e quais idiomas utilizados durante o processo de referência.

A respeito dos meios utilizados para a comunicação com o usuário (Tabela 5). A maioria respondeu ser por e-mail (98\%), seguido do telefone fixo (93\%), rede social $(63 \%)$, computador (55\%), página oficial da biblioteca na internet $(53 \%)$, telefone inteligente $(23 \%)$, chat $(20 \%)$, fax $(10 \%)$ e, tablete $(5 \%)$. No entanto, percebe-se que o e-mail e o telefone fixo são os principais meios de comunicação com a biblioteca. As redes sociais são utilizadas por mais da metade das bibliotecas, juntamente com os computadores e website oficial, enquanto, smartphones, chat, fax e tablete são pouco utilizados.

Tabela 5 - Meios de comunicação com o usuário

\begin{tabular}{lcc}
\hline $\begin{array}{c}\text { Meios utilizados para comunicação } \\
\text { com o usuário }\end{array}$ & Frequência absoluta & Frequência relativa (\%) \\
\hline Telefone fixo & 37 & 93 \\
Fax & 4 & 10 \\
Computador & 22 & 55 \\
Tablete (Tablet) & 2 & 5 \\
Telefone inteligente (Smartphone) & 9 & 23 \\
E-mail & 39 & 98
\end{tabular}


Rede social

Página oficial da biblioteca na internet

Chat
25

21

8
63

53

Fonte: Dados da pesquisa, 2016.

O uso de redes sociais pelo serviço de referência, demonstra-se no Gráfico 3 (três), onde aponta-se positivamente 55\% das bibliotecas inqueridas e negativamente $45 \%$ das bibliotecas. Sobre este questionamento, aplicou-se também da verificação, através da observação nos websites, das redes sociais divulgadas a partir dos websites oficiais, o resultado apresenta-se na Tabela 34, momento no qual far-se-á uma comparação do que foi revelado pelos bibliotecários e o que está exposto nos websites oficiais das bibliotecas investigadas.

\section{Gráfico 3- Uso de redes sociais pelo serviço de referência}

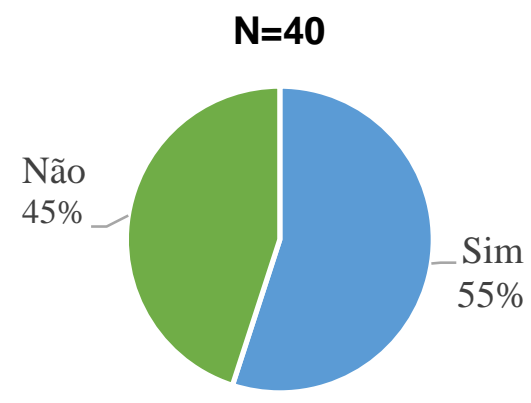

Fonte: Dados da pesquisa, 2016.

Em caso positivo à pergunta, pediu-se para que o respondente indicasse quais redes sociais eram utilizadas nas bibliotecas em que atuam. As respostas, detalhadas na Tabela 6, demostram que: 24 usam Facebook, 10 Twitter, três Flickr e Google + e, um Academia.edu. Na categoria outros, identificou-se: 2 blogs e 1 WhatsApp.

Tabela 6 - Redes sociais utilizadas pelas bibliotecas universitárias

\begin{tabular}{lcc}
\hline \multicolumn{1}{c}{$\begin{array}{c}\text { Redes sociais utilizadas pela } \\
\text { biblioteca }\end{array}$} & Frequência absoluta & Frequência relativa (\%) \\
\hline Facebook & 24 & 96 \\
Twitter & 10 & 40 \\
Flickr & 3 & 12 \\
Google + & 3 & 12 \\
Academia.edu & 1 & 4 \\
Outros & 3 & 12 \\
\hline Funções para utilização de redes & Frequência absoluta & Frequência relativa (\%) \\
sociais pelo serviço de referência. & & \\
\hline
\end{tabular}




\begin{tabular}{|c|c|c|}
\hline Interagir com o usuário & 17 & 68 \\
\hline Divulgar seus produtos, serviços & 24 & 96 \\
\hline \multicolumn{3}{|l|}{ Buscar informações e manter-se } \\
\hline atualizado & 8 & 32 \\
\hline Buscar parcerias & 1 & 4 \\
\hline Comunicar-se & 16 & 64 \\
\hline Atrair usuários & 17 & 68 \\
\hline $\begin{array}{l}\text { Agentes disseminadores de } \\
\text { informações em plataformas } \\
\text { digitais }\end{array}$ & Frequência absoluta & Frequência relativa (\%) \\
\hline Bibliotecário (a) & 40 & 100 \\
\hline Auxiliar de biblioteca & 8 & 20 \\
\hline Auxiliar/ Assistente administrativo & 9 & 23 \\
\hline Outros & 2 & 5 \\
\hline $\begin{array}{c}\text { Idiomas utilizados no processo de } \\
\text { referência }\end{array}$ & Frequência absoluta & Frequência relativa (\%) \\
\hline Português & 40 & 100 \\
\hline Inglês & 18 & 45 \\
\hline Espanhol & 6 & 15 \\
\hline
\end{tabular}

Fonte: Dados da pesquisa, 2016.

Para compreender a finalidade do uso dessas ferramentas, indagou-se acerca das funções do uso das redes sociais. Sendo assim, o resultado obtido (Tabela 6) indica que $96 \%$ afirmam utilizar as redes sociais para divulgar seus produtos e serviços, $68 \%$ disseram ser para interagir com o usuário ou atrair usuários, 64\% apontaram que é para se comunicar, 32\% para buscar informações e manter-se atualizado e, $4 \%$ buscar parcerias. Assim, de acordo com os resultados, revela-se que a maioria dos bibliotecários utilizam as redes sociais para divulgação de produtos e serviços, ao passo que a minoria busca parcerias através das redes sociais.

A respeito dos agentes disseminadores, explicitados em números na Tabela 6, aponta-se para uma maioria de bibliotecários (100\%), seguido de auxiliares administrativos (23\%), auxiliares de biblioteca $(20 \%)$ e, outros (indicados como estagiários, $5 \%$ ). Percebe-se que a totalidade dos respondentes afirmaram serem os bibliotecários os principais agentes disseminadores de informações. Vale ressaltar que a pergunta é caracterizada como de múltipla escolha, e com isto percebe-se que os bibliotecários trabalham com a cooperação de auxiliares administrativos e auxiliares de bibliotecas.

Uma pergunta de extrema importância dentro de um serviço de referência refere-se ao idioma adotado, isto porque a maioria da literatura científica encontra-se disponibilizada em língua inglesa. 
Autores de países cuja cultura e idioma nativo não são o inglês enfrentam dificuldades adicionais em redigir e submeter seus artigos a periódicos internacionais, uma vez que o inglês se estabeleceu como língua franca da ciência mundial (NASSICALÒ, 2014, p.1).

O estudo evidencia, na Tabela 6 , que todos os bibliotecários utilizam a língua portuguesa, 45\% a língua inglesa e, 15\% a língua espanhola durante os processos de referência. O resultado de $45 \%$ para língua inglesa releva-se um aspecto preocupante do processo de busca pela informação, principalmente pelo facto da maior parte da comunicação em ciência se dar em língua inglesa.

Importa esclarecer que o processo de internacionalização de profissionais e estudantes na academia brasileira é algo incipiente e o idioma é uma das barreiras predominantes durante as investigações científicas.

É preciso flexibilizar as regras e abrir as portas das universidades para estrangeiros, não obrigando-os a falar português, mas fomentando o uso do inglês entre os brasileiros, seja na sala de aula, nos laboratórios, ou nas chamadas de projetos e contratações (ESCOBAR, 2013, p.1).

O uso do inglês é cada vez mais requerido com a internacionalização das universidades, exigindo do bibliotecário competências linguísticas, não só em língua inglesa, mas nas línguas que a universidade interage com outras nacionalidades. Assim, ganha a ciência, abre-se novas possibilidades e os usuários estarão cada dia mais integrados com seu ambiente de pesquisa, propiciando maior aprendizado da visão local para comparar com suas experiências e fazer acadêmico.

\section{CONCLUSÕES}

O presente estudo revela a caracterização dos bibliotecários de referência brasileiros e do meio no qual ocorrem os serviços de referência. Com vistas à assimilar quem são estes profissionais, pode-se afirmar que são, em sua maioria, pertencentes ao sexo feminino, com idades entre 35 e 40 anos, pós-graduadas há no máximo dez anos, com formação superior em Biblioteconomia atuando em biblioteca universitária, há no máximo, dez anos e em serviços de referência há no máximo cinco anos, ligadas a alguma biblioteca central ou sistema de bibliotecas e que buscam a capacitação contínua, em cursos, treinamentos e eventos na área em que atua, em curtos períodos. 
Neste sentido, observa-se que a maioria feminina, está em idade predominantemente ativa e faz parte da geração de "nativos digitais". Esta é caracterizada por preferir um acesso à informação mais interativo, como o possibilitado pelo hipertexto, ao invés da forma linear e sequencial do texto impresso, funcionar melhor quando em rede e realizando atividades colaborativas e querer entretenimento unido à educação (PRENSKY, 2001). Os dados afirmam também que são profissionais que buscam o conhecimento através da capacitação contínua, treinamentos realizados periodicamente e participação em eventos. Sendo assim, a maioria absoluta de bibliotecários, demonstra o comprometimento do profissional e da instituição com as normas vigentes e a melhoria contínua dos serviços prestados.

Após a caracterização da população investigada, relevam-se as características dos SR, com foco no meio digital. Neste sentido, identificaram aspectos relativos ao meio onde ocorrem os $\mathrm{SR}$, às plataformas digitais utilizadas, a áreas do conhecimento mais acessadas pelos usuários por meio do $\mathrm{SRD}$, os principais tipos de fontes de informações que a biblioteca disponibiliza, além de características inerentes ao processo de comunicação.

As características ressaltadas pelos bibliotecários brasileiros sobre os questionamentos acerca dos serviços de referência revelam que ocorrem em meio digital e presencial. As principais fontes informacionais são o periódico, as teses e as dissertações, disponibilizadas e acessadas por meio dos recursos informacionais portal de periódicos eletrônicos e bases de dados, principalmente pelas áreas da saúde e biológicas. O processo de comunicação para a transação de referência ocorre predominantemente com a utilização de e-mail e telefone fixo, as redes sociais são utilizadas pela maioria das BUB, sendo o Facebook e o Twitter as mais empregadas, principalmente na divulgação de produtos e serviços, ou seja, para marketing e estratégias de promoção/publicidade. A comunicação é realizada por bibliotecários, prevalecendo-se da língua portuguesa. Contudo, para além de ferramenta de marketing digital dessas bibliotecas universitárias, vemos que os serviços de referência também estão sendo utilizados para atender à necessidade informacional dos usuários.

Contudo, pode-se se dizer que os serviços de referência em bibliotecas 
universitárias brasileiras estão em plena expansão, tecnologias estão sendo inseridas à prática bibliotecária e os bibliotecários estão em busca de qualificação profissional com vistas a melhoria dos serviços que ofertam nas bibliotecas que atuam. Muitas lacunas são observadas e, com isto, novas pesquisas devem ser realizadas para que evoluamos neste campo. Conhecer mais sobre o usuário desses serviços e como eles se comportam é algo que deve ser primordial aos profissionais que atuam em serviços de referência, focando no aprendizado ao longo da vida e na capacitação contínua.

\section{REFERÊNCIAS}

ACCART, J.-P. Serviço de referência: do presencial ao virtual. Brasília: Briquet de Lemos, 2012.

ARAÚJO, E. A.; DIAS, G. A. A atuação profissional do bibliotecário no contexto da sociedade de informação: os novos espaços de informação. In: OLIVEIRA, Marlene de (Coord.). Ciência da informação e biblioteconomia: novos conteúdos e espaços de atuação. Belo Horizonte: UFMG, 2005. p. 111-122.

ARELLANO, M. A. M. Serviços de referência virtual. Ciência da Informaçao, Brasília, v. 30, n. 2, p. 7-15, 2001.

BRASIL. PRESIDÊNCIA DA REPÚBLICA. Lei nº 4.084, 1962. Disponível em: http://www.planalto.gov.br/ccivil_03/leis/1950-1969/L4084.htm

CARVALHO, L. M.; SILVA, A. M. Impacto das tecnologias digitais nas bibliotecas universitárias: reflexôes sobre o tema. Informacao \& Sociedade: estudos, João Pessoa, p. 125-132, 2009.

CUNHA, M. B. Construindo o futuro: a biblioteca universitária brasileira em 2010. Ciência da Informação, Brasília, v. 29, n. 1, p. 71-89, 2000.

DUDZIAK, E. A. Information literacy: princípios, filosofia e prática. Ciência da Informação, v. 32, n. 1, p. 23-35, jan./ abr., 2003, Disponível em:

http://doi.org/10.1590/S0100-19652003000100003. Acesso em: 25 nov. 2020.

ESCOBAR, H. Universidades brasileiras devem promover internacionalização, valorizar mérito, flexibilizar regras e reduzir burocracia se quiserem chegar à elite do ensino superior. Ensino Superior Unicamp, Campinas, out. 2013.

FIGUEIREDO, N. M. DE. Textos avançados em referência e informação. São Paulo: Polis, 1996. 
GREEN, S. S. Personal relations between librarians and readers. Library Journal, [S.I.], v. 1, p. 74-81, 1876.

GROGAN, D. A prática do serviço de referência. Brasília: Briquet de Lemos, 1995.

JANES, J.; CARTER, D.; MEMMOTT, P. Digital reference services in academic libraries. Reference \& Users Services Quarterly, [S.I.], v. 39, n. 2, 1999.

JOHNSON, C. M. Online Chat Reference: survey results from affiliates of two universities. Reference \& Users Services Quarterly, [S.I.], v. 43, n.3, p. 237247, 2004.

LOPES, MARILI. I .; SILVA, E. L. DA. As bibliotecas universitárias e a mediação da informação na comunicação cientííica. SEMINÁRIO NACIONAL DE BIBLIOTECAS UNIVERSITÁRIAS, 14. Anais [...] Salvador: UFBA, 2006. Disponível em: http://www.snbu2006.ufba.br/soac/ viewabstract.php?id=87

MERLO-VEGA, J.-A. Referencia digital: concepto, tecnologías e implementación en centros de información. El Profesional de la Informacion, [S.I.], v. 18, n. 6, p. 589-600, nov. 2009.

MESQUITA, A. G. Serviços de referência: do tradicional ao digital nas bibliotecas dos Institutos Politécnicos públicos em Portugal. Coimbra: Universidade de Coimbra, 2011.

MORAN, C. The utility of digital reference services in academic libraries : an annotated bibliography. INFO522: Information Access \& Resources. Drexel University, USA, 2010. Disponível em: http://www.pages.drexel.edu/ cem325/docs/ab.pdf. Acesso em: 25 nov. 2020.

MOTA, A. R. S; BORGES, M. M. Os serviços de referência em bibliotecas universitárias brasileiras. In: ENCUENTRO IBÉRICO EDICIC 2019, 9. 2019. Barcelona, Espanha. Anais [...] Barcelona: Universidade de Barcelona, 2019. Disponível em: 10.31219/osf.io/6y5aw. Acesso em: 25 nov. 2020.

MOTA, F. R. L.; OLIVEIRA, M. In: OLIVEIRA, M. Ciência da informação e biblioteconomia: novos conteúdos e espaços de atuação. Belo Horizonte: Ed. UFMG, 2005.

NASSI-CALÒ, L. Autores cujo idioma nativo não é o inglês e editores, avaliam dificuldades e desafios para publicar em periódicos internacionais. SciELO em Perspectiva, [S.I.], 2014.

PRENSKY, M. Digital Natives, Digital Immigrants. On the Horizon, [S.I.], v. 9, n. 5, 2001.

SAMPIERI, R. H.; COLLADO, C. F.; LÚCIO, P. B. Metodologia de pesquisa. 5. ed. Porto Alegre: Penso, 2013. 
SILVA, E. L.; LOPES, M. I. A internet, a mediação e a desintermediação da informação. DataGrama Zero - Revista de Ciểncia da Informação, v. 12, n. 2 , 2011.

TARAPANOFF, K.; SUAIDEN, E.; OLIVEIRA, C. L. Funções sociais e oportunidades para profissionais da informação. DataGramaZero - Revista de Ciência da Informação, v. 3, n. 5, p. 1-11, 2002.

VITORINO, E. V.; PIANTOLA, D. Competência informacional - bases históricas e conceituais : construindo significados. Ciência da Informaçao, Brasília v. 38, n. 3, p. 130-141, 2009.

\title{
REFERENCE SERVICES IN BRAZILIAN UNIVERSITY LIBRARIES
}

\begin{abstract}
Introduction: the reference services have evolved and changed since the introduction of information and communication technologies in the academic environment. Since its emergence, at the end of the 19th century, great changes have occurred, especially when referring to access to the enormous range of data and information available. The article addresses concepts of reference services and portrays reference services in Brazilian university libraries. Objective: to characterize Brazilian reference librarians and the environment in which reference services take place. Methodology: integrates elements of qualitative and quantitative research. For data collection, a questionnaire was used, prepared and made available digitally to 40 librarians working in reference services of Brazilian university libraries. Results: reveal a majority, female, aged between 35 and 40 years, post-graduated for a maximum of ten years, with higher education in librarianship working in a university library for a maximum of ten years, and in reference services for, at most maximum, five years, linked to a central library or library system and seeking continuous training, in courses, training and events in the area in which it operates, in short periods. Reference services take place digitally and in person, the main information sources are the periodical, theses and dissertations, made available and accessed through information resources and the portal of electronic journals and databases, mainly in the areas of health and biological. The communication process for the reference transaction occurs predominantly with the use of e-mail and landline, social networks are used by most libraries, with Facebook and Twitter being the most used, mainly in the dissemination of products and services. Communication is carried out by librarians, using the Portuguese language. Conclusions: the reference services in Brazilian university libraries are in full expansion, technologies are being inserted into librarian practice and librarians are looking for professional qualification with a view to improving the services they offer in the libraries in which they operate.
\end{abstract}

Descriptors: Reference Service. University Library. Management of Services in Libraries.

\section{SERVICIOS DE REFERENCIA EN BIBLIOTECAS UNIVERSITARIAS DE BRASIL}




\section{RESUMEN}

Introducción: los servicios de referencia han evolucionado y cambiado desde la introducción de las tecnologías de la información y la comunicación en el entorno académico. Desde su aparición, a fines del siglo XIX, se han producido grandes cambios, especialmente cuando se hace referencia al acceso a la enorme variedad de datos e información disponibles. El artículo aborda conceptos de servicios de referencia y retrata servicios de referencia en bibliotecas universitarias brasileñas. Objetivo: caracterizar a los bibliotecarios de referencia brasileños y el entorno en el que se realizan los servicios de referencia. Metodología: integra elementos de investigación cualitativa y cuantitativa. Para la recolección de datos, el cuestionario se utilizó, preparó y puso a disposición digital a 40 bibliotecarios que trabajan en servicios de referencia de bibliotecas universitarias brasileñas. Resultados: revelan una mayoría, mujeres, con edades comprendidas entre 35 y 40 años, posgrado por un máximo de diez años, con educación superior en biblioteconomía trabajando en una biblioteca universitaria por un máximo de diez años, y en servicios de referencia para máximo, cinco años, vinculado a una biblioteca central o sistema de bibliotecas y buscando capacitación continua, en cursos, capacitación y eventos en el área en la que opera, en períodos cortos. Los servicios de referencia tienen lugar digitalmente y en persona, las principales fuentes de información son las publicaciones periódicas, tesis y disertaciones, disponibles y accesibles a través de recursos de información y el portal de revistas electrónicas y bases de datos, principalmente en las áreas de salud y biológico El proceso de comunicación para la transacción de referencia ocurre predominantemente con el uso de correo electrónico y teléfono fijo, las redes sociales son utilizadas por la mayoría de las bibliotecas, siendo Facebook y Twitter las más utilizadas, principalmente en la difusión de productos y servicios. La comunicación es realizada por bibliotecarios, utilizando el idioma portugués. Conclusiones: los servicios de referencia en las bibliotecas universitarias brasileñas están en plena expansión, las tecnologías se están insertando en la práctica del bibliotecario y los bibliotecarios están buscando una calificación profesional con miras a mejorar los servicios que ofrecen en las bibliotecas en las que operan.

Descriptores: Servicio de Referencia. Biblioteca de la universidad. Gestión de servicios en bibliotecas.

Recebido em: 22.01.2020

Aceito em: 03.09.2020 